\title{
CORRESPONDENCE
}

\section{'Switching' in bipolar disorder}

Following the helpful article in APT on hypomania in clinical practice (Smith \& Ghaemi, 2006), I want to draw attention to a phenomenon that I believe is more than an artefact and has clinical relevance. I have called it 'switching', for want of a better term, and use it to describe the following: established bipolar disorder (I or II in DSM-IV; American Psychiatric Association, 1994) with a present pattern of illness that is exclusively (or almost exclusively) isolated biphasic episodes in which one phase is followed by the opposite without, or with an extremely brief, intervening period of euthymia. This is distinguished from 'rapid-cycling' by the relatively isolated nature of the biphasic switch and failure to meet the frequency criterion of rapid cycling. People showing switching certainly exist, as I have treated them, but they are not frequent: whether they are unusual or extremely rare is hard to establish, as it is difficult to find an appropriate keyword with which to search the literature. Epidemiological studies do not as yet appear to distinguish them.

In 1854 Jean Pierre Falret wrote of folie circulaire, with a clear description of manic excitement and depression and the 'switch' from one to the other:

'un cercle continuel de depression et d'exitation maniaque et d'un intervalle de lucidité, que d'ordinaire et assez court' (Falret, 1854).

It is possible that Falret's syndrome, a little-used eponym describing a bipolar disorder in which

'a brief period of normality may be present between the two states, but in the majority of cases transition is direct' (http://www.whonamedit.com/synd. $\mathrm{cfm} / 2472 . \mathrm{html})$

actually refers to switching.

In correspondence, Daniel Smith kindly drew my attention to papers by Akiskal (2005), Benazzi (2006) and Judd et al (2003). Akiskal notes that

'Mood lability - with rapid shifts, often in a depressive polarity - was the hallmark of unipolar patients who switched to bipolar II'.

Benazzi and Akiskal identified the phenomenon of biphasic switching, that is one episode immediately followed by an opposite pole episode, where these episodes occurred at least once when the patient was not taking antidepressants. In their series of patients with bipolar II disorder, $80 \%$ were biphasic.

Judd et al found shifts in affective polarity, defined as 'a week-to-week change in polarity', and noted that about $20 \%$ of the sample had changed status once in a year. However, it is not clear whether they are referring to a biphasic switch or to separated phases during the year.

These three studies of bipolar disorder were actually of bipolar II, rather than the more typical bipolar I, form.

In his correspondence with me, Smith considered that 'switching' could be explained in other ways, phenomenologically. Individuals might be experiencing extremes of mixed states, a condition which is more common than originally thought. A mixed state with a preponderance of mania, for example, might change quite suddenly into one in which depression predominates. Obviously, definition is crucial: the Research Diagnostic Criteria (Spitzer et al, 1978) defined mixed states in 1978 and recognised two patterns: in the second pattern, manic and major depressive episodes followed one another without interruption, which corresponds to switching. The DSM-III-R (American Psychiatric Association, 1987) defined mixed states as the sum of symptoms of mania and major depression occurring over a period of 1 week or more either concomitantly or in rapid alteration every few days: this could also be a variant of switching. In DSM-IV, however, mixed states are defined in a much more restricted way.

A switch from depression to mania might also be explained by the well-known phenomenon of hypomania following antidepressant treatment (including electroconvulsive therapy).

Finally, switching might simply be isolated rapid cycling that does not therefore meet the definition of rapid cycling. It is unlikely that the phenomenon can be explained as a variant of cyclothymia, since the episodes are often severe and psychotic.

I believe there is clinical utility in isolating the phenomenon of switching. It carries important information, essential to the proper management of bipolar disorder. This is particularly the case in switching that passes from mania to depression, as depression in bipolar disorder carries a greater risk of suicide. Although difficult to prove, it is credible that states of depression that occur very rapidly and severely, changing from hypomania or mania into psychotic depression over the space of days or even hours, are particularly likely to give rise to suicidality. It is not unknown in my experience to encounter patients who did in fact follow just this course, with hypomanic phases terminating in sudden depressive switches in which they developed depressive fugues and made serious suicide attempts. Such patients are 
particularly difficult to maintain in the community by the care programme approach, but recognising the biphasic nature of their condition allows the first phase to be identified as a relapse indicator.

Switching that passes very quickly from depression into mania can initially be misinterpreted. An individual with severe depression who suddenly makes a miraculous recovery may have this type, when the false remission is rapidly revealed to be a manic episode.

Switching is relevant if a patient appeals to a mental health review tribunal. At the time of the tribunal the patient may be mildly hypomanic, failing to pass the criterion of 'degree' of mental illness sufficient to continue to detain, for the patient's own health or safety. The prior identification that the individual is in a mental state that will shortly switch to severe depression, with all the resulting hazards, is enough to establish a criterion for detention through the 'nature' of the condition (nature and degree need be only disjunctive).

There would seem to be good reasons for studying the epidemiology of this phenomenon by those who are able to set up large-scale series of patients with bipolar disorder.

\section{Declaration of interest}

None.

Akiskal, H. S. (2005) The dark side of bipolarity: detecting bipolar depression in its pleomorphic expressions. Journal of Affective Disorders, 84, 107-115.

American Psychiatric Association (1987) Diagnostic and Statistical Manual of Mental Disorders (3rd edn, revised) (DSM-III-R). Washington, DC: APA.

American Psychiatric Association (1994) Diagnostic and Statistical Manual of Mental Disorders (4th edn) (DSM-IV). Washington, DC: APA.

Benazzi, F. (2006) Mood patterns and classification in bipolar disorder. Current Opinion in Psychiatry, 19, 1-8.

Falret, J.-P. (1854) Mémoire sur la folie circulaire. Bulletin de l'Académie Nationale de Medicine, 19, 382-400.

Judd, L. L., Akiskal, H. S., Schettler, P. J., et al (2003) A prospective investigation of the natural history of the long-term weekly symptomatic status of bipolar II disorder. Archives of General Psychiatry, 60, 261-269.

Smith, D. J. \& Ghaemi, S. N. (2006) Hypomania in clinical practice. Advances in Psychiatric Treatment, 12, 110-120.

Spitzer, R. L., Endicott, J. \& Robins, E. (1978) Research Diagnostic Criteria (RDC) for a Selected Group of Functional Disorders (3rd edn). New York: Biometrics Research, New York State Biometrics Institute.

R. L. Symonds Consultant Psychiatrist and Medical Member, Mental Health Tribunals (c/o Advances in Psychiatric Treatment, Royal College of Psychiatrists, 17 Belgrave Square, London SW1X 8PG, UK. Email: r.l.symonds@dsl.pipex.com). 